Academic Platform Journal of Engineering and Science

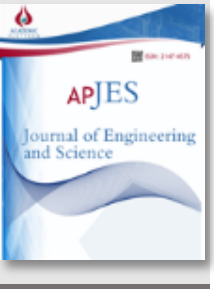

\title{
Kitosan-Vermikülit Kompoziti Kullanılarak Sulu Çözeltiden Etkin Kurşun Giderimi: Denge, Kinetik ve Termodinamik Çalışmalar
}

\author{
${ }^{1}$ Zeynep Mine Şenol \\ ${ }^{1}$ Cumhuriyet Üniversitesi, Zara Ahmet Çuhadaroğlu MYO, Gıda İşleme Bölümü, 58140 Sivas, Türkiye, \\ msenol@ cumhuriyet.edu.tr, iD \\ Araștırma Makales \\ Geliş Tarihi: 24.02.2019 \\ Kabul Tarihi: 29.08.2019
}

$\ddot{O} z$

Bu çalışmada, sulu çözeltiden kurşun iyonlarının etkin giderimi için düşük maliyetli, doğal etkin bir adsorban, kitosan (Ch) vermikülit (V) kompozit materyali sentezlenmiştir. Ch-V kompoziti FT-IR SEM-EDX ve PZC analizleri ile karakterize edilmiştir. $\mathrm{Pb}^{2+}$ için $\mathrm{Ch}-\mathrm{V}$ kompozitinin adsorban özellikleri adsorpsiyonun $\mathrm{pH}$, derişim, kinetik (zaman), termodinamik (sıcaklık) ve geri kazanım açısından değerlendirilmiştir. Elde edilen deneysel veriler Langmiur, Freundlich ve Dubinin Radushkevich izoterm modellerine uygulanmış ilgili parametreler türetilmiştir. Langmiur eiştliğinden maksimum adsorpsiyon kapasitesi 0.154 molkg$^{-1}$ ve $\mathrm{K}_{\mathrm{L}}$ değeri ise $3441 \mathrm{Lmol}^{-1}$ olarak bulunmuştur. Freudlich modelinden adsorpsiyon kapasitesinin bir ölçüsü olan $\mathrm{X}_{\mathrm{F}} 10.3$ ve $\beta$ yüzey heterojenliği ise 0.537 bulunmuştur. Sonuçlar deneysel verilerin Freundlich modeline daha iyi

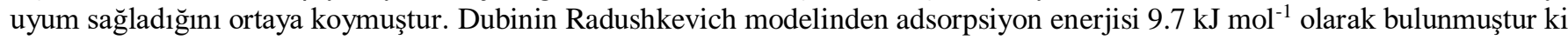
bu durum adsorpsiyon sürecinin kimyasal olduğunu ifade etmektedir. Adsorpsiyon kinetiğinin yalancı ikinci derece modele uyum sağladığı görülmüştür. Adsorpsiyonun termodinamik değerlendirilmesinden $\Delta \mathrm{H}^{0}$ değeri $5.09 \mathrm{kjmol}^{-1}$ bulunmuştur ki bu durum adsorpsiyonun endotermik olduğunu işaret eder. $\Delta \mathrm{S}^{0}$ ise $69.7 \mathrm{Jmol}^{-1} \mathrm{~K}^{-1}$ olarak bulunmuştur ki bu durum adsorpsiyon sürecinde biyosorbent/çözelti arayüzündeki rastgelelikte bir artma olduğunu gösterir. $298.15{ }^{0} \mathrm{C}$ için Gibbs serbest enerji değişimi, $-15.7 \mathrm{~kJ} \mathrm{~mol}^{-1}$ olarak bulunmuştur ve bu durum adsorpsiyonun kendiliğinden olduğunu göstermiştir. Geri kazanım çalışmaları Ch-V kompozitinin iyi bir adsorpsiyon/desorpsiyon performansına sahip olduğunu göstermiştir.

Anahtar Kelimeler: Kitosan, vermikülit, kompozit, adsorpsiyon, kurşun

\section{Efficient Lead Removal from Aqueous Solution Using Chitosan-Vermiculite Composite: Equilibrium, Kinetic and Thermodynamic Studies}

\author{
Zeynep Mine Şenol \\ ${ }^{1}$ Cumhuriyet Üniversitesi, Zara Ahmet Çuhadaroğlu MYO, Gıda İşleme Bölümü, 58140 Sivas, Türkiye, \\ msenol@cumhuriyet.edu.tr
}

\begin{abstract}
In this study, a cost effective, naturally effective adsorbent, chitosan (Ch) - vermiculite (V) composite material for the efficient removal of lead ions from aqueous solution was synthesized. The $\mathrm{Ch}-\mathrm{V}$ composite was characterized by FT-IR SEM-EDX and PZC analyzes. The adsorbent properties of $\mathrm{Ch}-\mathrm{V}$ composite for $\mathrm{Pb}^{2+}$ were evaluated in terms of $\mathrm{pH}$, concentration, kinetic (time), thermodynamic (temperature) and recovery of adsorption. The experimental data obtained are derived from the relevant parameters applied to the Radushkevich isotherm models of Langmiur, Freundlich and Dubinin. The maximum adsorption capacity was found to be $0.154 \mathrm{~mol} \mathrm{~kg}^{-1}$ and the $\mathrm{K}_{\mathrm{L}}$ value was $3441 \mathrm{Lmol}^{-1}$. Freudlich model is a measure of adsorption capacity $\mathrm{X}_{\mathrm{F}} 10.3$ and $\beta$ surface heterogeneity is 0.537 . The results showed that the experimental data fit better with the Freundlich model. The adsorption energy of Dubin Radushkevich model was found to be $9.7 \mathrm{~kJ} \mathrm{~mol}^{-1}$, which indicates that the adsorption process is chemical. Adsorption kinetics were found to adapt to the pseudo-second model. The olduğun $\Delta \mathrm{H} 0$ value of adsorption was

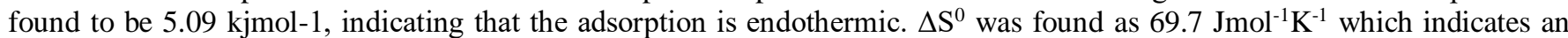
increase in the randomness of the biosorbent/solution interface during the adsorption process. Gibbs free energy exchange for
\end{abstract}


$298.15^{\circ} \mathrm{C}$ was found to be $-15.7 \mathrm{~kJ} \mathrm{~mol}^{-1}$, indicating that adsorption was spontaneous. The recovery studies showed that the $\mathrm{Ch}$ $\mathrm{V}$ composite had good adsorption/desorption performance.

Keywords: Chitosan, Vermiculite, Composite, Adsorption, Lead

\section{GİRIŞ}

Sulu çözeltilerden ağır metal iyonlarının giderimi halk sağlığı ve çevre güvenliği açısından oldukça önemlidir. Çünkü ağır metal iyonları biyolojik olarak parçalanamazlar. Hem çevre kirliliğine neden olan hem de insan sağlığına zarar veren ağır metallerin giderimi ve aynı zamanda geri kazanımı oldukça önemlidir. Çevre kirliliğine neden olan ağır metallerden biri de kurşundur. Kurşun, genelde metal, metal kaplama sanayi ve madencilik faaliyetleri atık sularında bulunur. Bu atık sular çevreye verilmeden önce arıtılmaları gerekmektedir. Ağır metaller atık sulardan adsorpsiyon, ters ozmos, iyon değişimi, membran filtrasyon ve kimyasal çöktürme gibi işlemler yoluyla kimyasal ya da fiziksel olarak uzaklaştırılırlar. [1] Atık sulardan ağır metal iyonlarının gideriminde adsorpsiyon yöntemi, verimliliği ve uygulama kolaylığı açısından oldukça ilgi çekicidir. Bu durum düşük maliyetli ve doğal adsorbanların kullanımını yaygınlaştırmıştır. Atık sulardan ağır metal iyonlarının gideriminde bentonit [2], zeolit [3], diatomit [4], vermikülit [5], dolomit [6] gibi doğal mineraller ile kitosan [7], lignin [8] gibi doğal polimerler yaygın olarak kullanılan adsorbanlardandır. Vermikülit mika mineralleri ve kloritin alterasyonu sonucu oluşan 2:1 tabakalı fillosilikat mineralidir. Vermikülit $\quad \mathrm{Mg}_{3}(\mathrm{AlSi})_{4} \mathrm{O}_{10}(\mathrm{OH})_{2} \mathrm{X} 4 \mathrm{H}_{2} \mathrm{O}$ kimyasal formülüne sahiptir. Türkiye'de bol bulunan ve maliyeti düşük doğal minerallerden olan vermikülitin son yıllarda ağır metal adsorpsiyonunda kullanımını yaygınlaşmıştır.Kitosan, kitinin deasetilasyonu sonucu elde edilen, doğada selülozdan sonra en çok bulunan, suda çözünebilen bir aminopolisakkarittir. Doğaya ve insana zararı olmayan antibakteriyel, antifungal etkilere sahiptir. Kitosan tekstilde, kozmetikte, tıbbi malzemelerin yapımında ve tarım alanları gibi pek çok sektörde kullanılmaktadır. Bunların yanı sıra çevre kirliliğini önlemek amacıyla adsorban olarak da kullanılmaktadır [9].

Bu çalışmada; doğal bir mineral olan vermikülit ile doğal bir polimer olan kitosanın, Ch-V kompoziti sentezlenmiş ve sulu ortamdan kurşun iyonunun giderimi için adsorban özellikleri araştırılmıştır. Ch-V kompoziti FT-IR SEM-EDX ve $\mathrm{PZC}$ analizleri ile karakterize edilmiştir. $\mathrm{Pb}^{2+}$ için $\mathrm{Ch}-\mathrm{V}$ kompozitinin adsorban özellikleri adsorpsiyonun $\mathrm{pH}$, derişim, kinetik (zaman), termodinamik (sıcaklık) ve geri kazanım açısından değerlendirilmiştir.

\section{MATERYAL ve METOT}

\subsection{Kimyasallar ve Cihazlar}

$\mathrm{Pb}^{2+}$ iyonunun adsorpsiyon araştırmasında $\mathrm{Pb}\left(\mathrm{NO}_{3}\right)_{2}$ ve bu iyonun spektrofotometrik ölçümlerinde kompleksleştirici madde olarak 4-(2-pridilazo) resorkinol, PAR ve diğer kimyasallar Merk'den (Germany) temin edilmiştir. Tüm deneylerde ultra saf su kullanılmıştır. Tüm deneyler daima çiftli çalışılmıştır. Vermikülit minerali Sivas-Yıldızeli bölgesinden temin edilmiştir. $\mathrm{Ch}-\mathrm{V}$ ve bileşenleri FT-IR (Perkin Elmer 400) ve SEM-EDX (Leo 440 Computer Controlled Digital) analizleriyle karakterize edilmiştir. Kurşun derişimi UV-VIS spektrofotometre (UV-VIS spektrofotometre, SHIMADZU, 160 A model, Japonya) kullanılarak belirlenmiştir. Bu spektrofotometre 190-1100 $\mathrm{nm}$ dalgaboyu aralığında $\pm 0.2 \mathrm{~nm}$ ve $2 \mathrm{~nm}$ dalga boyu hassaslığına sahiptir. pH değerlerini ölçmek için camkalomel elektrotlu bir pH metre (Selecta, İspanya) kullanılmıştır. Faz ayrımını hızlandırmak için santrifüj (Hettich Universal) kullanıldı. Sıcaklığı sabit tutmak için termostatlı bir su banyosu (NuveNT 120, Türkiye) kullanılmıştır.

\subsection{Ch-V Kompozitinin Sentezi}

Yaklaşık 4 g Ch-V kompoziti sentezlemek için 2 g kitosan ve $2 \mathrm{~g}$ vermikülit karışımı \% 5 (v/v)'lik asetik asit çözeltisinde 2 saat boyunca homojen bir karışım elde edinceye dek karıştırıcıda karıştırılmış daha sonra Epiklorohidrin $(\mathrm{ECH})$ çözeltisi eklenmiş ve karıştırılmaya devam edilmiştir. Karışım daha sonra sodyumtripolifosfat (NaTPP) çözeltisine damla damla eklenerek kompozit boncuklar oluşturulmuştur. Elde edilen boncuklar yıkama suyunun iletkenliği yaklaşık saf su iletkenliğine ulaşana kadar saf su ile yıkanmıştır. $40{ }^{0} \mathrm{C}^{\prime}$ de etüvde kurutulan örnekler tanecik boyutu 50 mesh olacak şekilde öğütülmüş ve daha sonra kullanılmak üzere kapalı kaplarda saklanmıştır.

\subsection{Kesikli (Batch) Adsorpsiyon Prosedürü}

Sentezlenen $\mathrm{Ch}-\mathrm{V}$ kompozitinin $\mathrm{Pb}^{2+}$ iyonu için adsorpsiyon özellikleri; pH 1-5, başlangıç metal derişimi 25-800 ppm $\left[(0.12-3.9) \times 10^{-3} \mathrm{~mol} \mathrm{~L}^{-1}\right]$, etkileşim süresi (kinetik) 2-1440 $\mathrm{dk}$, sicaklık (termodinamik) 5,25 ve $40{ }^{\circ} \mathrm{C}$ ve desorpsiyon açısından değerlendirilmiştir. Deneyler $0.1 \mathrm{~g}$ adsorban ve 10 $\mathrm{mL} 500 \mathrm{mg} \mathrm{L}^{-1}\left(2.4 \times 10^{-3} \mathrm{~mol} \mathrm{~L}^{-1}\right)$ sabit derişimimde $\mathrm{Pb}^{2+}$ içeren $10 \mathrm{~mL}$ 'lik polipropilen tüplerde $140 \mathrm{rpm}$ çalkalama hızında gerçekleştirilmiştir. Adsorban-çözelti sistemleri 24 saat boyunca 298 K'de bir termostatik su banyosu içinde dengelenmiş ve denge çözeltileri sulu fazı elde edilmiştir. $\mathrm{Pb}^{2+}$ iyonu derişimi absorbans ölçümü ile belirlenmiştir. $\mathrm{Pb}^{2+}$ derişimleri bu iyonun PAR ile oluşturduğu kompleksin $\lambda=518,5 \mathrm{~nm}$ 'de spektrofotometrik yöntemle ölçülmesiyle saptanmıştır [10]. Elde edilen verilerden \% Adsorpsiyon ve $\left.\mathrm{Q}(\mathrm{mol} \mathrm{kg})^{-1}\right), \%$ Adsorpsiyon $=\left[\frac{C_{i}-C_{f}}{C_{i}}\right] x 100$ ve $Q=$ $\left[\frac{C_{i}-C_{f}}{m}\right] x V$ eşitlikleri ile hesaplanmıştır. Burada $\mathrm{C}_{\mathrm{i}}$; 
biyosorplananın başlangıç derişimini $\left(\mathrm{mg} \mathrm{L}^{-1}\right), \mathrm{C}_{\mathrm{f}}$; denge derişimini ( $\left.\mathrm{mg} \mathrm{L}^{-1}\right), \mathrm{m}$; adsorban kütlesini $(\mathrm{g}), \mathrm{V}$ ise çözelti hacmini (L) tanımlamaktadır.

\section{BULGULAR VE TARTIŞMA}

\subsection{FT-IR Analiz Sonuçları}

Ch-V kompozitinin adsorpsiyon öncesi ve sonrası FT-IR spektrumları Şekil 1'de görülmektedir. Ch-V kompozitine ait spektrum incelendiğinde, $456 \mathrm{~cm}^{-1}$ de $\mathrm{Si}-\mathrm{O}$ absorpsiyon band1, $673 \mathrm{~cm}^{-1}$ deki Al-O piki, $962 \mathrm{~cm}^{-1}$ de ise Si-O ait absorpsiyon bandları görülmektedir ki bunlar vermikülüt için karakteristik piklerdir [11]. 3290-3350 $\mathrm{cm}^{-1}$ arası $\mathrm{OH}$ bandlar1, 1650 ve $1575 \mathrm{~cm}^{-1}$, de C-O pikleri, $1070 \mathrm{~cm}^{-1}$, de $\mathrm{N}-\mathrm{H}$ grupları ve $2864 \mathrm{~cm}^{-1}$ 'de NH gruplarına ait karakteristik Ch pikleri görülmektedir [12]. Ek olarak 1640-3400 $\mathrm{cm}^{-1}$ dalga boyları arasındaki geniş bandın ise $\mathrm{HOH}$ ve $\mathrm{OH}$ gruplarına ait piklerdir. Ch-V kompozitinde hem Ch'a hem de V'e ait piklerin görülmesi yani her iki bileşene ait karakteristik pikleri içermesi $\mathrm{Ch}-\mathrm{V}$ kompozitinin başarılı bir şekilde sentezlendiğinin kanıtıdır. Ch-V kompozitinin adsorpsiyon öncesi ve sonrası spektrumları karşılaştırıldığında, piklerin yeri değişmemekle beraber pik şiddetlerinde azalma görülmektedir. $\mathrm{Bu}$ durum $\mathrm{Pb}^{2+}$ iyonu ile Ch-V kompoziti yüzeyindeki fonksiyonel gruplar arasındaki elektrostatik etkileşimlerden kaynaklanmaktadır. $\mathrm{Bu}$ sonuçlar yukarıda belirtilen $\mathrm{Ch}-\mathrm{V}$ kompozitinin fonksiyonel gruplarına $\mathrm{Pb}^{2+}$ adsorpsiyonunu kanıtlamaktadır.

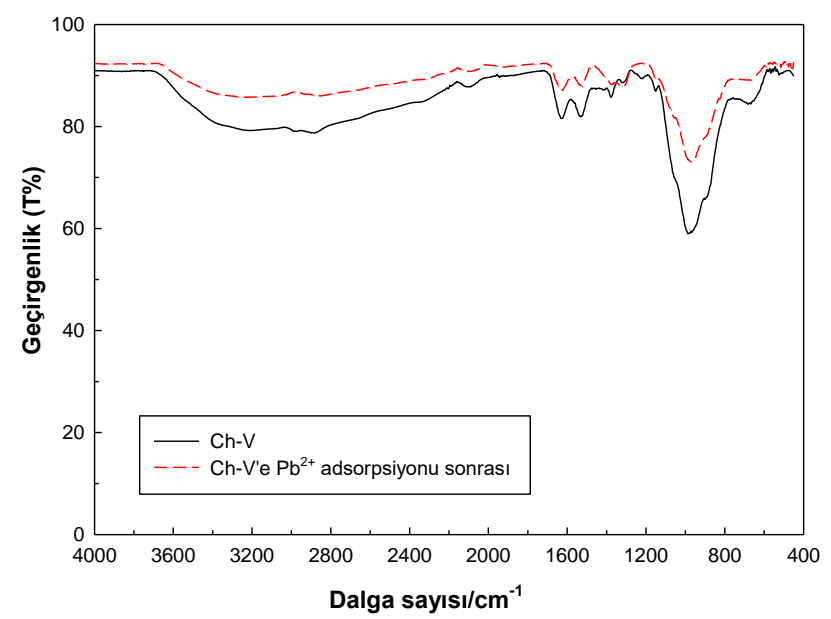

Şekil 1. Ch-V'e $\mathrm{Pb}^{2+}$ adsorpsiyonu öncesi ve sonrası FT-IR spektrumları

\subsection{SEM/EDX Analiz Sonuçları}

Adsorbanın yüzey morfolojisindeki farklılıkları belirlemek için SEM analiz tekniği kullanılmıştır. Şekil 2 (a) ve (b) de $\mathrm{Ch}-\mathrm{V}$ kompozit adsorbanına $\mathrm{Pb}^{2+}$ adsorpsiyonu öncesi ve sonrası SEM görünümleri görülmektedir. Şekil $(a, b)$ incelendiğinde $\mathrm{Ch}-\mathrm{V}$ kompozit adsorbanının yüzey morfolojisinde değişiklik olduğu açıkça görülmektedir. Ch$\mathrm{V}$ kompozit adsorbanının yüzeyinde adsorpsiyon sonrası $\mathrm{Pb}^{2+}$ iyonlarının toplandığı görülmektedir. $\mathrm{Bu}$ durum $\mathrm{Pb}^{2+}$ iyonları ve Ch-V kompozit adsorbanının yüzeyindeki fonksiyonel gruplar arasındaki elektrostatik etkileşimler ve yüzey kompleksleşmesinden kaynaklanmış olabilir. Şekil 2 (c) ve (d) de likene $\mathrm{Pb}^{2+}$ adsorpsiyonu öncesi ve sonrası EDX sonuçları görülmektedir. Şekil 2 (c)' deki sonuçlara göre, Ch$\mathrm{V} \mathrm{C}, \mathrm{O}, \mathrm{Si}, \mathrm{Mg}, \mathrm{Al}, \mathrm{Fe}, \mathrm{Ti}$ ve $\mathrm{K}$ elementlerinden oluşmaktadır. Diğer taraftan Şekil 2 (d)'de Ch-V kompozitinine ait tüm elementlerin yanı sıra görülen $\mathrm{Pb}$ içeriği Ch-V'e $\mathrm{Pb}^{2+}$ adsorpsiyonuna delildir.

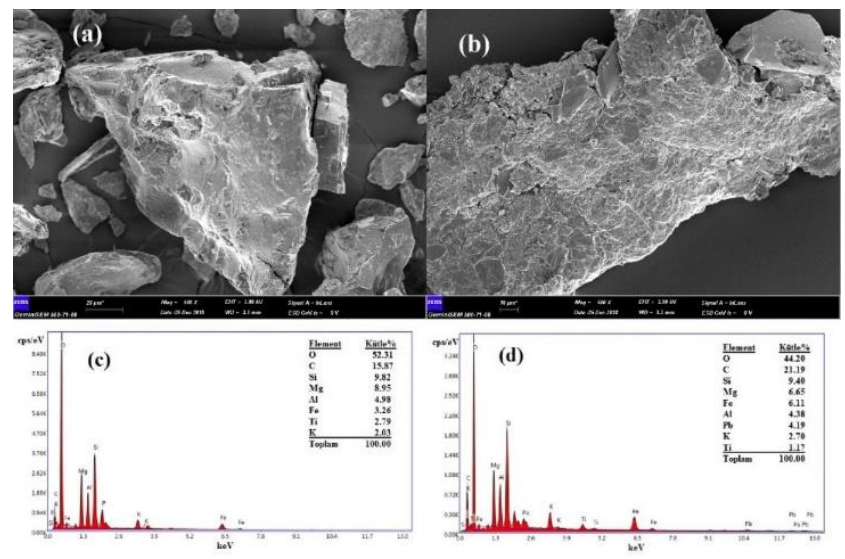

Şekil $2 \mathrm{~Pb}^{2+}$ adsorpsiyonu öncesi (a) ve sonrası (b) SEM fotoğrafları ve $\mathrm{Pb}^{2+}$ adsorpsiyonu öncesi (c) ve sonrası (d) EDX sonuçları

\subsection{Adsorpsiyona pH Etkisi}

Adsorpsiyon mekanizması çözelti içindeki türlerin fizikokimyasal etkileşimleriyle ilgilidir. Sulu çözelti pH'sı adsorbana metal iyonları adsorpsiyonunu etkileyen en önemli parametredir. Çözelti pH'sı, adsorban yüzeyindeki aktif merkezlere metal iyonlarıyla hidrojen iyonlarının rekabet yetenekleriyle doğrudan ilişkilidir. Yüksek asidik pH'larda, metal katyonları ve hidrojen iyonları aktif bölgelere bağlanmak için yarışırlar ve bu da metalin daha az adsorpsiyonuna sebep olur. Yüksek bazik pH'larda ise, metal iyonlarının çözünebilir hidroksit kompleksleri oluşur ve bu da adsorpsiyonu azaltır.

Ch-V kompozitine $\mathrm{Pb}^{2+}$ iyonları adsorpsiyonu üzerine $\mathrm{pH}$ etkisi ile ilgili sonuçlar Şekil 3'de sunulmuştur. Sonuçlar adsorpsiyonun artan $\mathrm{pH}$ ile arttığını göstermiştir. pH'nın 1'den 5'e çıkarılmasılyla adsorpsiyonun da \%5'den \% 84'e çıktığı görülmüştür. Maksimum adsorpsiyon $\mathrm{pH}=4.5^{\prime} \mathrm{de} \%$ 84 olarak bulunmuştur. $\mathrm{pH} 4.5, \mathrm{~Pb}^{2+}$ çözeltisinin doğal $\mathrm{pH}$ '1 olup adsorpsiyonun en yüksek olduğu $\mathrm{pH}$ olarak bulunmuştur. $\mathrm{Bu}$ nedenle, tüm adsorpsiyon çalışmalarında $\mathrm{Pb}^{2+}$ iyonunun kendi pH'sında çalışılmıştır. pH 5 ve üzerindeki çözelti pH'larında $\mathrm{Pb}^{2+}$ iyonlarının hidroksitleri şeklinde çökmesi nedeniyle çalışılmamıştır.

Adsorbanın yüzey yükünün sıfır olduğu çözelti pH değeri, Sıfır Yük Noktası (SYN) olarak tanımlanır. Ch-V'nin SYN değerlerini belirlemek için adsorban, $\mathrm{pH}=1-12$ aralığındaki çözeltilerde 24 sa bekletilmiş ve denge pH'ları ölçülmüştür. Sonuçlar Şekil 4'de verilmiştir. Ch-V kompozit adsorbanının 
yüzeyi $\mathrm{pH} 4.76$ altında pozitif, $\mathrm{pH} 4.76$ üstünde ise negatif bulunmuştur. Ch-V'nin yüzey yükü artan $\mathrm{pH}$ ile negatife gidecektir.

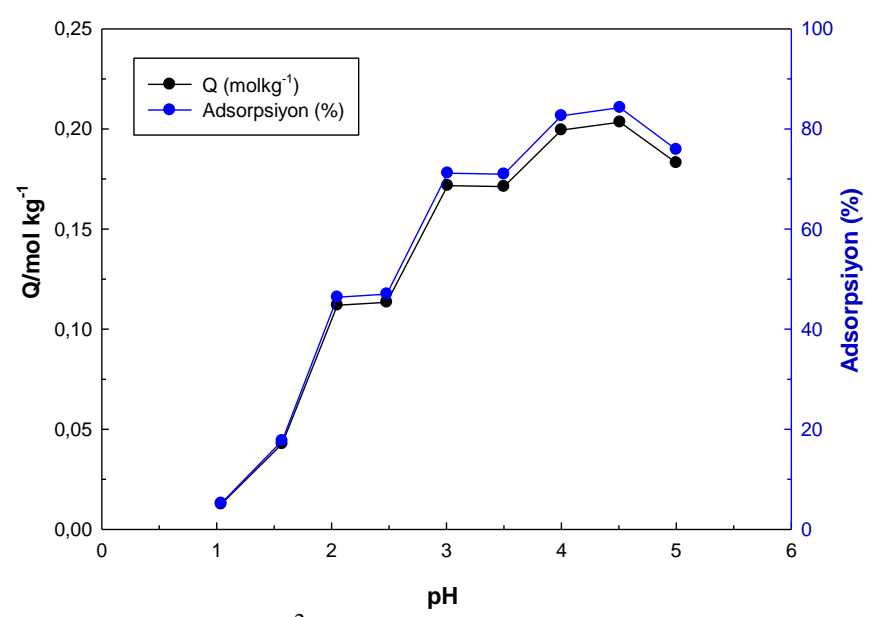

Şekil 3. Ch-V'ye $\mathrm{Pb}^{2+}$ adsorpsiyonunun $\mathrm{pH}$ ile değişimi $\left\{\left[\mathrm{Pb}^{2+}\right]_{0}=500 \mathrm{ppm}\right.$, Adsorban kütlesi $=0.1 \mathrm{~g}, \mathrm{~V}=10 \mathrm{~mL}$, etkileşim süresi: 24 sa

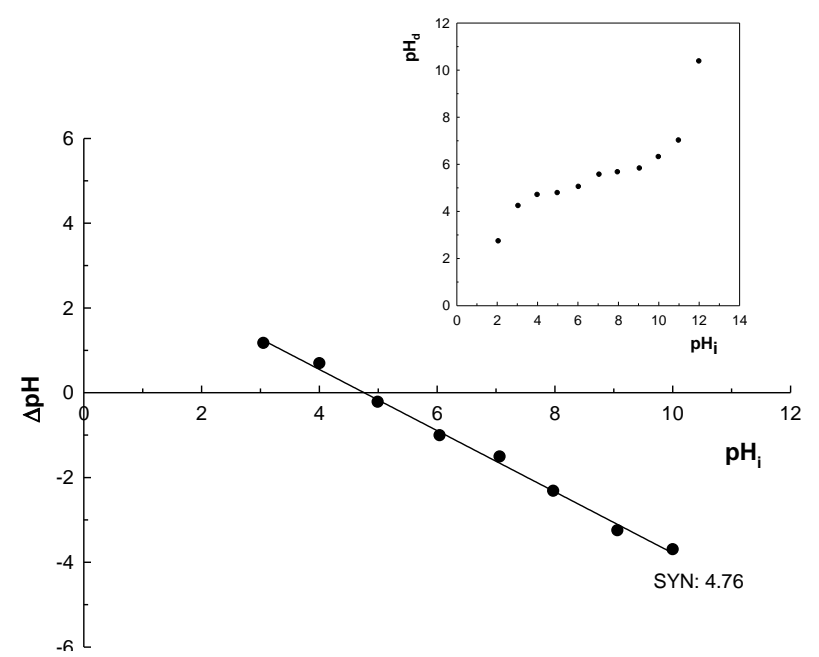

Şekil 4. Ch-V için SYN grafiği

\subsection{Adsorpsiyon Sürecinin Modellenmesi}

Adsorpsiyon sürecini modellemek için deneysel yolla elde edilen veriler, üç yaygın adsorpsiyon modeline; Langmuir, Freundlich ve Dubinin-Radushkevich izoterm modellerine uygulandı ve ilgili parametreler türetildi. Adsorpsiyonun gerçekleştiği aktif merkezlerin adsorban yüzeyinde homojen dağılımda olduğu varsayan Langmuir izoterm modeline göre elde edilen deneysel verilerin, $Q=\frac{K_{L} X_{m} C_{e}}{1+K_{L} C_{e}}$ eşitliğine uyumu araştırılır. Burada $\mathrm{Q}\left(\mathrm{mol} \mathrm{kg}{ }^{-1}\right)$ adsorplanan miktar, $\mathrm{C}_{\mathrm{e}}(\mathrm{mol}$ $\mathrm{L}^{-1}$ ) denge derişimi, $\mathrm{X}_{\mathrm{m}}$ adsorbanın maksimum adsorpsiyon kapasitesi, $\mathrm{K}_{\mathrm{L}}$ dağılım katsayısını ifade eder. [13]. Freundlich izoterm modeli ise hiperbolik bir adsorpsiyon davranışını açıklamakla birlikte adsorban yüzeyinin heterojenliği ile ilgili bilgi verir ve deneysel verilerin, $Q=$
$K_{f} C_{e}^{\beta}$ eşitliğine uyumu araştırılır, burada $\mathrm{K}_{\mathrm{f}}$ adsorpsiyon kapasitesinin bir ölçüsü, $\beta$ ise adsorban yüzey heterojenliğini ifade eder [14]. Dubinin-Radushkevich (D-R) modeli de adsorpsiyonun yüzey gözenekliliği ve gözenek hacmi ile ilgili olduğu varsayımını esas alan bir modeldir. Adsorpsiyonu enerjetik açıdan inceleyen ve $Q=$ $X_{D R} e^{-K_{D R} \varepsilon^{2}}$ ile verilen D-R denkleminde, adsorplanan $\mathrm{Q}$ miktarı $\left(\mathrm{mol} \mathrm{kg}^{-1}\right)$, adsorpsiyon kapasitesinin bir ölçüsü olan $\mathrm{X}_{\mathrm{DR}}$, aktivite katsayısı $\mathrm{K}_{\mathrm{DR}}\left(\mathrm{mol}^{2} \mathrm{~K} \mathrm{~J}^{2}\right)$ ve Polanyi potansiyeli (ع) ile ilgilidir. Polanyi potansiyeli ise $\varepsilon=R T \ln (1+$ $\left.\frac{1}{C_{e}}\right)$ kullanılır ve $\mathrm{R}$, ideal gaz sabiti $\left(8.314 \mathrm{~J} \mathrm{~mol}^{-1} \mathrm{~K}^{-1}\right)$ ve $\mathrm{T}$ $(\mathrm{K})$ ise mutlak sicaklıktır. Adsorpsiyon enerjisi (E) ise; $E=$ $\left(2 K_{D R}\right)^{-0.5}$ eşitliği ile hesaplanır. $\mathrm{E}\left(\mathrm{kJmol}^{-1}\right)$ değeri, adsorpsiyon mekanizmasını fiziksel veya kimyasal olarak belirtir. Adsorpsiyon enerjisi, $8<\mathrm{E}<16 \mathrm{kJmol}^{-1}$ ise adsorpsiyonun kimyasal kontrollü ve $\mathrm{E}<8 \mathrm{kJmol}^{-1}$ ise adsorpsiyonun fiziksel olarak ilerlediğini gösterir $[15,16]$. $\varepsilon^{2} \times 10^{-9}$

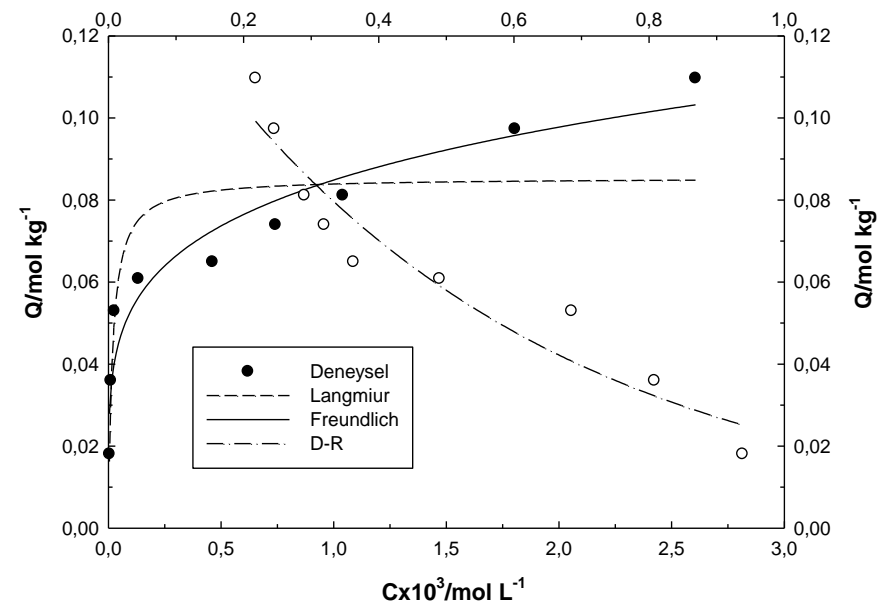

Şekil 5. Ch-V'ye $\mathrm{Pb}^{2+}$ adsorpsiyonunun derişimle değişimi ve bunun Langmuir, Freundlich ve D-R modellerine uyumu $\left\{\left[\mathrm{Pb}^{2+}\right]_{0}=25-800 \mathrm{ppm}\right.$, Adsorban kütlesi $=0.1 \mathrm{~g}, \mathrm{~V}=10 \mathrm{~mL}$, etkileşim süresi:24 sa $\}$

Tablo 1. Langmuir, Freundlich ve Dubinin-Radushkevich izoterm modellerinden türetilen parametreler

\begin{tabular}{|l|l|l|l|l|l|}
\hline \multicolumn{2}{|c|}{ Langmuir } & \multicolumn{2}{c|}{ Freundlich } & \multicolumn{2}{c|}{ D-R } \\
\hline $\mathrm{X}_{\mathrm{m}} / \mathrm{mol} \mathrm{kg}^{-1}$ & 0.154 & $\mathrm{~K}_{\mathrm{f}}$ & 10.3 & $\mathrm{X}_{\mathrm{DR}}$ & 1.50 \\
\hline $\mathrm{K}_{\mathrm{L}} / \mathrm{L} \mathrm{mol}^{-1}$ & 3441 & $\beta$ & 0.537 & $-\mathrm{K}_{\mathrm{DR}} 10^{6}$ & 5.29 \\
\hline $\mathrm{R}^{2}$ & 0.880 & $\mathrm{R}^{2}$ & 0.930 & $\mathrm{R}^{2}$ & 0.930 \\
\hline & & & & $\mathrm{E} / \mathrm{kJ} \mathrm{mol}^{-1}$ & 9.7 \\
\hline
\end{tabular}

Şekil 5'de Langmuir, Freundlich ve D-R izoterm modellerine uyum, Tablo 1'de ise bu modellerden türetilen parametreler yeralmaktadır. Langmuir ve Freundlich izoterm modellerinden türetilen $\mathrm{R}^{2}$ değerleri kıyaslandığında, Ch$\mathrm{V}^{\prime} \mathrm{Pb}^{2+}$ adsorpsiyonun Freundlich modeline daha iyi uyum sağladığı görülmüştür. Freudlich modelinden adsorpsiyon kapasitesinin bir ölçüsü olan $\mathrm{K}_{\mathrm{f}} 10.3$ ve $\beta$ yüzey heterojenliği ise 0.537 bulunmuştur. Lngmuir modelinden maksimum adsorpsiyon kapasitesi $0.154 \mathrm{~mol} \mathrm{~kg}^{-1}$ ve $\mathrm{K}_{\mathrm{L}}$ değeri ise 3441 $\mathrm{L} \mathrm{mol}^{-1}$ olarak bulunmuştur. Sonuçlar deneysel verilerin 
Langmiur modeline iyi uyum sağlamadığını ortaya koymaktadır. D-R modelinden adsorpsiyon enerjisi $9.7 \mathrm{~kJ}$ $\mathrm{mol}^{-1}$ olarak bulunmuştur ki bu durum adsorpsiyon sürecinin kimyasal olduğu anlamına gelir.

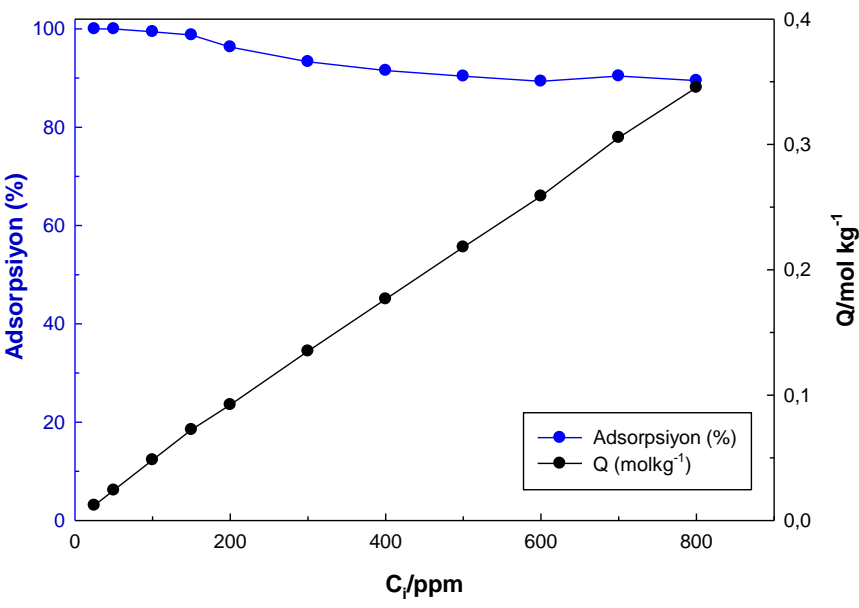

Şekil 6. Adsorpsiyona derişim etkisi

Şekil 6'da \% Adsorpsiyon ve Q (mol kg-1) değerlerinin başlangıç derişimi ile değişimimi gösterilmiştir. \% adsorpsiyon

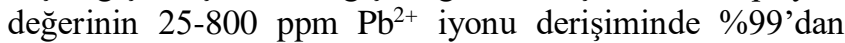
\%89'a düştüğü görülmektedir. Düşük $\mathrm{Pb}^{2+}$ iyonu derişimlerinde daha yüksek adsorpsiyon olduğu, başlangıç $\mathrm{Pb}^{2+}$ iyonu derişiminin artmasıyla da Ch-V adsorbanı üzerindeki aktif adsorpsiyon alanları zamanla azaldığı ve doygunluğa ulaşmakta olduğu görülmektedir. Bu durum, başlangıç $\mathrm{Pb}^{2+}$ iyonu derişimi ile adsorban yüzeyi arasındaki kütle transferinin oldukça etkin bir parametre olmasındandır.

\subsection{Adsorpsiyon Kinetiği}

Kinetik parametrelerin belirlenmesi adsorpsiyon mekanizmasının açıklanmasına yardımcı olması açısından oldukça önemlidir. Bu amaçla yaygın olarak üç tip kinetik model kullanılır; Lagergren yalancı birinci derece (pseudofirst order kinetic model) [17], $Q_{t}=Q_{e}\left(1-e^{-k_{1} t}\right)$, yalanc1 ikinci derece (pseudo-second order kinetic model) [18, 19], $Q_{t}=\frac{t}{\left[\frac{1}{k_{2} Q_{e}^{2}}\right]+\left[\frac{1}{Q_{e}}\right] t}$ ve parçacık içi difüzyon modeli (Weber-Morris) $Q_{t}=k_{i} t^{0.5}$ denklemleriyle ifade edilen modeller kullanılır. Burada $\mathrm{Q}_{\mathrm{t}}\left(\mathrm{mol} \mathrm{kg}^{-1}\right) \mathrm{t}$ anında tutunan iyon miktarı ve $Q_{e}\left(m o l ~ \mathrm{~kg}^{-1}\right)$ denge anında tutunan iyon miktarıdır. $\mathrm{k}_{1}\left(\mathrm{~min}^{-1}\right)$ ve $\mathrm{k}_{2}\left(\mathrm{~mol} \mathrm{~kg} \mathrm{~min}{ }^{-1}\right)$ birinci ve ikinci dereceden hız sabitlerini sirasıyla gösterir. Adsorpsiyonun yalancı birinci derece modeli için başlangıç hızı $H_{1}=$ $k_{1} Q_{e}$ yalancı ikinci derece modeli için başlangıç hızı $H_{2}=$ $k_{2} Q_{e}^{2}$ eşitlikleri kullanılarak hesaplanmıştır [20]. Deneysel verilere Lagergren yalancı birinci derece, yalancı ikinci derece ve parçacık içi difüzyon modelleri uygulanmış ve ilgili parametreler türetilmiştir. Deneysel verilerin bu modellere uyumu Şekil 7'de bu modellerden türetilen kinetik parametreler ise Tablo 2'de sunulmuştur. Deneysel verilerin modellere uyumunu gösteren $\mathrm{R}^{2}$ değerleri incelendiğinde, yalancı ikinci derece modele uyum görülmektedir. Ayrıca, teorik olarak hesaplanan $\mathrm{Q}_{\mathrm{t}}$ ve deneysel $\mathrm{Q}_{\mathrm{e}}$ değerlerinin birbirlerine yakınlığ 1 da yalancı ikinci derece modele uyumu işaret etmektedir. Parçacık içi difüzyon modeli grafiği orjinden geçen tek bir doğrusal yerine iki doğrusal bileşenli olması, adsorpsiyon sürecinin yüzey ve yüzey içi difüzyon aşamalarını içerdiğini ifade etmektedir. $\mathrm{Bu}$ durumda adsorpsiyonun tek bir kinetik modelle açıklanmasının mümkün olmadığını göstermiştir. Adsorpsiyon kinetiği yalancı ikinci derece kinetik model ve parçacık içi difüzyon modelleriyle açıklanabilir [21]. Adsorbanın yüzeyi ilk önce kimyasal etkileşimlerle hızlı bir şekilde dolar ve daha sonra parçacık içi difüzyon işlemi yavaş yavaş başlar.

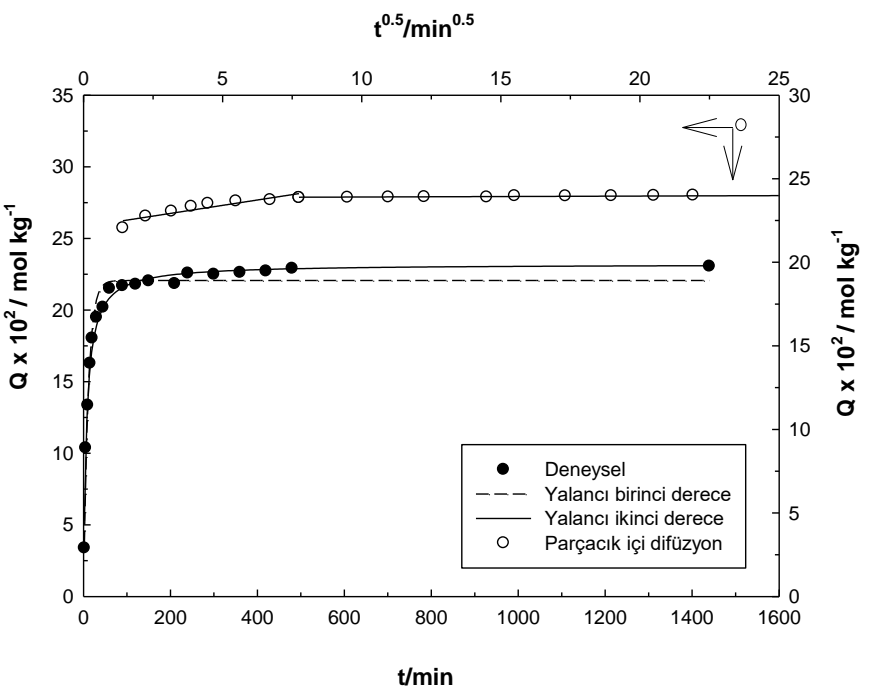

Şekil 7. Ch-V'ye $\mathrm{Pb}^{2+}$ adsorpsiyonunun yalancı birinci derece, yalancı ikinci ve Parçacık içi difüzyon modellerine uyumu $\left\{\left[\mathrm{Pb}^{2+}\right]_{0}=500 \mathrm{ppm}\right.$, Adsorban kütlesi $=0.3 \mathrm{~g}, \mathrm{~V}=30$ $\mathrm{mL}$, etkileşim süresi:24 sa\}

Tablo 2. Yalancı birinci derece, yalancı ikinci derece ve parçacık içine difüzyon hız modellerine uyumdan türetilen parametreler

\begin{tabular}{|l|c|c|c|c|c|}
\hline \multicolumn{1}{|c|}{$\mathbf{P b}^{\mathbf{2 +}}$} & $\begin{array}{c}\left(\mathbf{k}_{\mathbf{1}}, \mathbf{k}_{\mathbf{2}}, \mathbf{k}_{\mathbf{i}}\right) \\
\mathbf{x 1 0}^{\mathbf{3}}\end{array}$ & $\mathbf{R}^{\mathbf{2}}$ & $\mathbf{Q}_{\mathbf{t}}$ & $\mathbf{Q}_{\mathbf{e}}$ & $\mathbf{H x 1 0}^{\mathbf{3}}$ \\
\hline $\begin{array}{l}\text { Yalanc1 } \\
\text { birinci } \\
\text { derece }\end{array}$ & 92.7 & 0.974 & 0.231 & 0.221 & 20.5 \\
\hline $\begin{array}{l}\text { Yalanc1 } \\
\text { ikinci } \\
\text { derece }\end{array}$ & 633 & 0.987 & 0.231 & 0.232 & 34.1 \\
\hline $\begin{array}{l}\text { Parçacık içi } \\
\text { difüzyon }\end{array}$ & 2.57 & 0.843 & - & - & - \\
\hline
\end{tabular}

\subsection{Adsorpsiyon Termodinamiği}

Ch-V'e $\mathrm{Pb}^{2+}$ iyonu adsorpsiyonunun termodinamik davranışlarını açıklamak için 5,25 ve $40{ }^{\circ} \mathrm{C}$ sıcaklıklarda çalışılmıştır. Adsorpsiyon sırasındaki entalpi değişimi $\left(\Delta \mathrm{H}^{0}\right)$, entropi değişimi $\left(\Delta \mathrm{S}^{0}\right)$ ve serbest enerji değişimini $\left(\Delta \mathrm{G}^{0}\right)$ içeren termodinamik parametreler hesaplanmıştır. $\Delta \mathrm{G}^{0}$ serbest enerji değişimi $\Delta G=-R T \ln K_{D}$ eşitliğiyle hesaplanmıştır. Burada, R ideal gaz sabiti $\left(8.314 \mathrm{Jmol}^{-1} \mathrm{~K}^{-1}\right)$, $\mathrm{T}(\mathrm{K})$ sıcaklık ve $K_{D}=\frac{Q}{C_{e}}$ dağılım katsayısıdır $[22,23]$. Entalpi ve entropi parametreleri, $\ln K_{D}=\frac{\Delta S^{0}}{R}-\frac{\Delta H^{0}}{R T}$ eşitliği 
kullanılarak hesaplanmıştır. Şekil 8'in eğim ve kesimi kullanılarak $\Delta \mathrm{H}^{0}$ ve $\Delta \mathrm{S}^{0}$ hesaplanmıştır. $\Delta \mathrm{H}^{0}$ değeri $5.09 \mathrm{~kJ}$ $\mathrm{mol}^{-1}$ bulunmuştur ki bu durum adsorpsiyonun endotermik olduğunu işaret etmiştir. $\Delta \mathrm{S}^{0}$ ise $69.7 \mathrm{Jmol}^{-1} \mathrm{~K}^{-1}$ olarak bulunmuştur ki bu durum adsorpsiyon sürecinde adsorban/çözelti arayüzündeki rastgelelikte bir artma olduğunu göstermiştir. Gibbs serbest enerji değişimi, $\Delta G^{0}=$ $\Delta H^{0}-T \Delta S^{0}$ eşitliği kullanılarak hesaplanmıştır. Gibbs serbest enerji değişimi, sırasıyla 5,25 ve $40{ }^{\circ} \mathrm{C}^{\prime} \mathrm{de}-14.3$, 15.7 ve $-16.7 \mathrm{~kJ} \mathrm{~mol}^{-1}$ olarak hesaplanmıştır. Negatif $\Delta \mathrm{G}^{0}$ değeri adsorpsiyonun kendiliğinden olduğunu ve daha yüksek sıcaklıklarda kendiliğinden olma eğilimin arttığını göstermektedir.

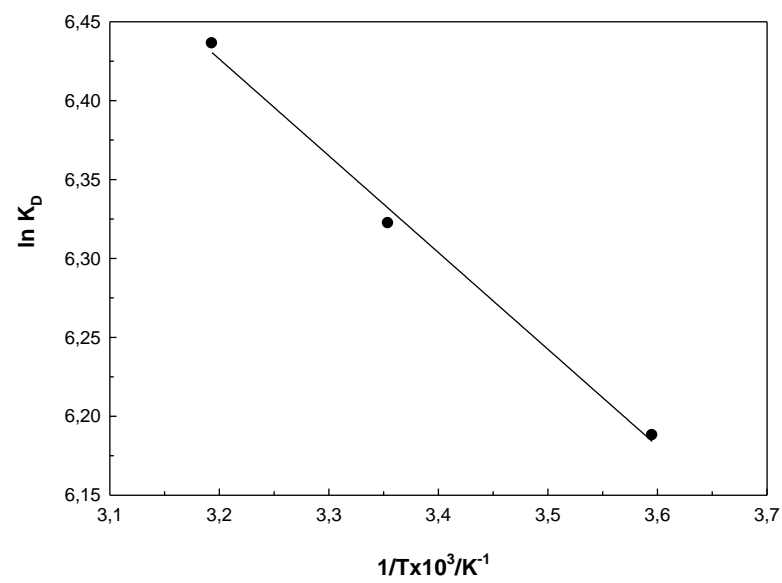

Şekil 8. Ch-V'ye $\mathrm{Pb}^{2+}$ adsorpsiyonuna sıcaklık etkisi $\left\{\left[\mathrm{Pb}^{2+}\right]_{0}=500 \mathrm{ppm}\right.$, Adsorban kütlesi $=0.1 \mathrm{~g}, \mathrm{~V}=10 \mathrm{~mL}$, etkileşim süresi: $24 \mathrm{sa}\}$

\subsection{Adsorpsiyona iyonik şiddet etkisi}

Ch-V'e $\mathrm{Pb}^{2+}$ iyonu adsorpsiyona iyonik şiddet etkisi $\mathrm{KNO}_{3}$ 'ün farklı derişimlerinde araştırılmıştır. Şekil 9'da $\mathrm{KNO}_{3}$ 'ün eklenmesiyle \% adsorpsiyonun azaldığ 1 görülmektedir. $\mathrm{Bu}$ durum $\mathrm{Ch}-\mathrm{V}$ kompozitinin aktif alanlarına adsorpsiyon için $\mathrm{K}^{+}$ile $\mathrm{Pb}^{2+}$ iyonlarının yarışması ile açıklanabilir.

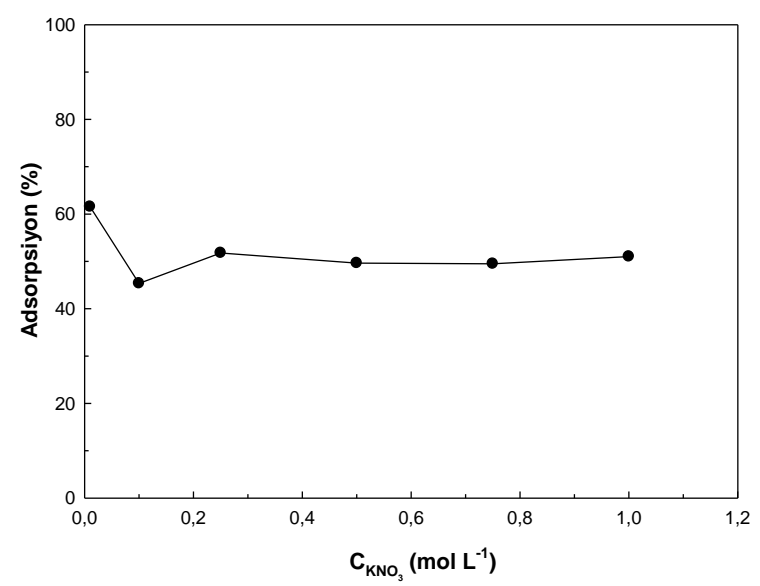

Şekil 9. Ch-V'ye $\mathrm{Pb}^{2+}$ adsorpsiyonuna iyonik şiddet etkisi $\left\{\left[\mathrm{Pb}^{2+}\right]_{0}=500 \mathrm{ppm}\right.$, Adsorban kütlesi $=0.1 \mathrm{~g}, \mathrm{~V}=10 \mathrm{~mL}$, etkileşim süresi:24 sa\}

\subsection{Geri Kazanım}

Adsorplanmış metalin geri kazanımı/desorpsiyonu adsorpsiyon sürecinin en önemli aşamalarından biridir. Adsorplanmış $\mathrm{Pb}^{2+}$ iyonlarının geri kazanım koşullarını değerlendirmek için $\mathrm{HCl}, \mathrm{NaOH}, \mathrm{HNO}_{3}$ ve Etil alkol ile bir dizi desorpsiyon deneyleri yapılmıştır ve Şekil 10'daki sonuçlar elde edilmiştir. Şekil 10'dan görüldüğü gibi $\mathrm{Pb}^{2+}$ iyonları için maksimum geri kazanım yüzdesi $\mathrm{HNO}_{3}(\%$ 99.2), en düşük eğri kazanım ise Etil alkol (\% 1.5) ile elde edilmiştir.

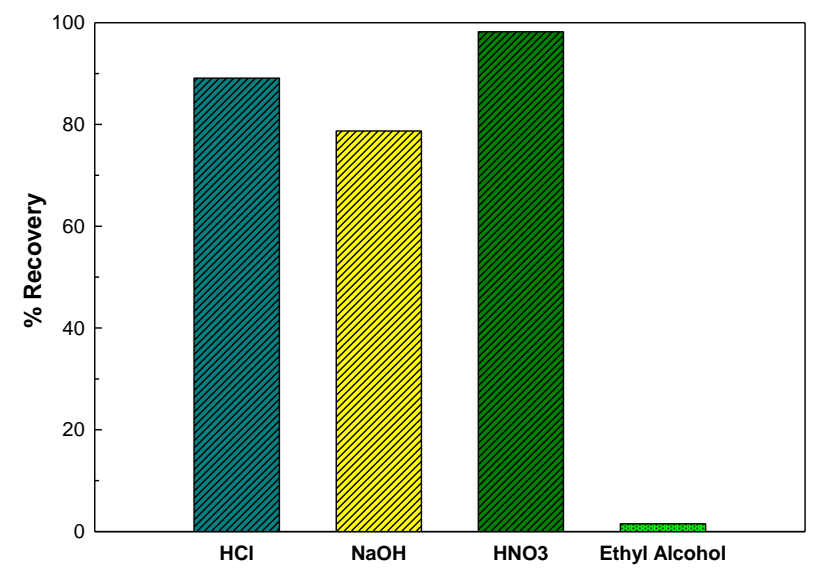

Şekil 10. $\mathrm{Pb}^{2+}$ iyonlarının desorpsiyonu için çeşitli solventlerin geri kazanım yüzdeleri

\section{DEĞERLENDİRME VE SONUÇ}

$\mathrm{Bu}$ çalışmada, Ch-V kompozit adsorbanı kullanılarak sulu çözeltiden $\mathrm{Pb}^{2+}$ giderimi için kesikli (batch) adsorpsiyon deneyleri yapılmıştır. Maksimum adsorpsiyon için optimal çalışma parametreleri; çözeltinin $\mathrm{pH}^{\prime}$ ', adsorban miktarı, temas süresi ve sicaklık, $\mathrm{pH} 4.5,0.1 \mathrm{~g}, 24$ sa ve $25{ }^{\circ} \mathrm{C}$ olarak seçilmiştir. Elde edilen deneysel veriler Langmuir, Freundlich ve D-R izoterm modellerine uyguland1. Optimal koşullarda tek tabaka adsorpsiyon kapasitesi 0.154 mol kg-1 bulundu. D-R izoterminden hesaplanan adsorpsiyon serbest enerjisi $\mathrm{E}_{\mathrm{DR}}\left(9.7 \mathrm{~kJ} \mathrm{~mol}^{-1}\right)$ olarak hesaplanmıştır ki bu durum Ch-V'e $\mathrm{Pb}^{2+}$ adsorpsiyonunun kimyasal iyon değişim mekanizması ile gerçekleştiğini ifade etmektedir. Negatif $\Delta \mathrm{G}^{0}$ değeri $\mathrm{Ch}-\mathrm{V}^{\prime} \mathrm{e} \mathrm{Pb}^{2+}$ adsorpsiyonunun mümkün ve kendiliğinden olduğunu gösterdi. Pozitif $\Delta \mathrm{H}^{0}$ değeri adsorpsiyonun endotermik doğasını betimlemektedir.

Pozitif $\Delta \mathrm{S}^{0}$ değeri adsorpsiyon sürecinde adsorban/çözelti arayüzündeki rastgelelikte bir artma olduğunu göstermektedir. Deneysel verilerin kinetik modellere uygulanmasıyla $\mathrm{Ch}-\mathrm{V}^{\prime} \mathrm{e} \mathrm{Pb}^{2+}$ adsorpsiyonunun yalancı ikinci 
dereceden ve parçacık içi diffüzyon hız kinetiğini izlediği bulunmuştur. Geri kazanım çalışmaları $\mathrm{Ch}-\mathrm{V}$ kompozitinin $\mathrm{Pb}^{2+}$ iyonu için iyi bir adsorpsiyon/desorpsiyon performansına sahip olduğunu göstermiştir.

\section{TEŞEKKÜR}

Bu çalışma (Proje no: ZARA004), Cumhuriyet Üniversitesi Bilimsel Araştırma Projeleri Komisyonu (CÜBAP) tarafindan desteklenmiştir.

\section{KAYNAKÇA}

[1] L. Jin and R. Bai, "Mechanisms of Lead Adsorption on Chitosan/PVA Hydrogel Beads," Langmuir, vol. 18, no. 25, pp. 9765-9770, 2002.

[2] F. Banat, B. Al-Bashir, S. Al-Asheh, and O. Hayajneh, "Adsorption of phenol by bentonite," Environmental Pollution, vol. 107, no. 3, pp. 391-398, 2000.

[3] V. Meshko, L. Markovska, M. Mincheva, and A. Rodrigues, "Adsorption of basic dyes on granular acivated carbon and natural zeolite," Water Research, vol. 35, no. 14, pp. 3357-3366, 2001.

[4] A. Sarı, D. Çıtak, and M. Tuzen, "Equilibrium, thermodynamic and kinetic studies on adsorption of $\mathrm{Sb}(\mathrm{III})$ from aqueous solution using low-cost natural diatomite," Chemical Engineering Journal, vol. 162, no. 2, pp. 521-527, 2010.

[5] T. Mathialagan and T. Viraraghavan, "Adsorption of Cadmium from Aqueous Solutions by Vermiculite," Separation Science and Technology, vol. 38, no. 1, pp. 57-76, 2003.

[6] A. B. Albadarin, C. Mangwandi, A. A. H. Al-Muhtaseb, G. M. Walker, S. J. Allen, and M. N. Ahmad, "Kinetic and thermodynamics of chromium ions adsorption onto low-cost dolomite adsorbent," Chemical Engineering Journal, vol. 179, pp. 193-202, 2012.

[7] R. Schmuhl, H. Krieg, and K. Keizer, "Adsorption of $\mathrm{Cu}(\mathrm{II})$ and $\mathrm{Cr}(\mathrm{VI})$ ions by chitosan: kinetics and equilibrium studies," Water SA, vol. 27, no. 1, 2004.

[8] X. Guo, S. Zhang, and X.-Q. Shan, "Adsorption of metal ions on lignin," Journal of Hazardous Materials, vol. 151, no. 1, pp. 134-142, 2008.

[9] M. Oktav Bulut and U. Elibüyük. "Yengeç kitininden kitosan üretimi," Erzincan University Journal of Science and Technology, vol. 10, no. 2, pp. 213-219, 2017.

[10] S. Şimşek, Z. M. Şenol, and H. I. Ulusoy, "Synthesis and characterization of a composite polymeric material including chelating agent for adsorption of uranyl ions," Journal of Hazardous Materials, vol. 338, pp. 437-
446, 2017.

[11] A. Pawlak and M. Mucha, "Thermogravimetric and FTIR studies of chitosan blends," Thermochimica Acta, vol. 396, no. 1-2, pp. 153-166, 2003.

[12] S. Gu, L. Wang, X. Mao, L. Yang, and C. Wang, "Selective Adsorption of $\mathrm{Pb}$ (II) from Aqueous Solution by Triethylenetetramine-Grafted

Polyacrylamide/Vermiculite," Materials, vol. 11, no. 4, p. 514, 2018.

[13] K. Foo and B. Hameed, "Insights into the modeling of adsorption isotherm systems," Chemical Engineering Journal, vol. 156, no. 1, pp. 2-10, 2010.

[14] H.M.F. Freundlich. "Over the adsorption in solution." The Journal of Physical Chemistry, vol. 57, no. 1, pp. 385-471, 1906.

[15] M.M. Dubinin, E.D. Zaverina, L.V. Radushkevich. "Sorption and structure of active carbons I. Adsorption of organic vapors." Zhurnal Fizicheskoi Khimii, vol. 21, no. 1, pp. 1351-1362, 1947.

[16] F. Helfferich. "Ion exchange." New York: McGraw Hill, 1962.

[17] S. Lagergren. "Zur theorie der sogenannten adsorption gel"oster stoffe." K. Sven. Vetenskapsakad. Handl, vol. 24, no. 1, pp. 1-39, 1898.

[18] Y. Ho and G. Mckay, "Pseudo-second order model for sorption processes," Process Biochemistry, vol. 34, no. 5, pp. 451-465, 1999.

[19] Y. Ho, "The kinetics of sorption of divalent metal ions onto sphagnum moss peat," Water Research, vol. 34, no. 3, pp. 735-742, 2000.

[20] Y. Ho and A. Ofomaja, "Pseudo-second-order model for lead ion sorption from aqueous solutions onto palm kernel fiber," Journal of Hazardous Materials, vol. 129, no. 1-3, pp. 137-142, 2006.

[21] F.-C. Wu, R.-L. Tseng, and R.-S. Juang, "Initial behavior of intraparticle diffusion model used in the description of adsorption kinetics," Chemical Engineering Journal, vol. 153, no. 1-3, pp. 1-8, 2009.

[22] R. Aravindhan, J. R. Rao, and B. U. Nair, "Removal of basic yellow dye from aqueous solution by sorption on green alga Caulerpa scalpelliformis," Journal of Hazardous Materials, vol. 142, no. 1-2, pp. 68-76, 2007.

[23] A. Sarı, M. Tuzen, and M. Soylak, "Adsorption of Pb(II) and $\mathrm{Cr}$ (III) from aqueous solution on Celtek clay," Journal of Hazardous Materials, vol. 144, no. 1-2, pp. 41-46, 2007. 